\title{
ESR Study of Copper Complexes Adsorbed on Fully Hydrated X and Y Zeolites
}

\author{
Giacomo Martini and M. Francesca Ottaviani \\ Istituto di Chimica Fisica, Università di Firenze, Firenze, Italy \\ (Z. Naturforsch. $33 \mathrm{~b}, 62-66$ [1978]; received October 12, 1977) \\ ESR, Cu(II) Complexes, Synthetic Zeolites
}

\begin{abstract}
The ESR spectroscopy is used for the study of the motion of $\mathrm{Cu}(\mathrm{en})_{2}{ }^{2+}$ and $\mathrm{Cu}(\mathrm{tmen})(\mathrm{OH})_{2}$ in fully hydrated $\mathrm{X}$ and $\mathrm{Y}$ zeolites. At room temperature steric hindrance in the faujasite cavities and slow motion condition lead to partially anisotropic spectra.

In frozen samples, calculation of bonding coefficients indicate small interaction with surface walls.
\end{abstract}

The electron spin resonance (ESR) line shape has been recently investigated in our laboratory in order to study the mobility of transition metal ions dissolved in water adsorbed on porous supports ${ }^{1-3}$.

Hydrated metal ions after adsorption on porous solids generally give rise to liquid-type ESR spectra in the motional narrowing region which allow to infer relevant information on the properties of water in highly disordered porous systems ${ }^{2}$ or in the almost regular crystal lattice of synthetic zeolites ${ }^{3}$.

Vacuum heating leads to migration of the metal ion into specific sites of the bulk of the solids or into different cavities of zeolites 4 . A lot of papers has been devoted, for instance, to the migration and localization of $\mathrm{Cu}^{2+}$ ions in the different sites of the zeolite cavities after vacuum heating ${ }^{5-10}$. The electron spin relaxation of $\mathrm{Cu}\left(\mathrm{H}_{2} \mathrm{O}\right)_{6}{ }^{2+}$ in the temperature region of fast motion after adsorption into hydrated zeolites has also been investigated ${ }^{3}$.

In this work we focus our attention on the motion and localization of large complexes of $\mathrm{Cu}(\mathrm{II})$ adsorbed in the faujasite cavities of fully hydrated $\mathrm{X}$ and $\mathrm{Y}$ zeolites and a comparison with the behaviour of $\mathrm{Cu}\left(\mathrm{H}_{2} \mathrm{O}\right)_{6}{ }^{2+}$ is made. Semiquantitative evaluation of the bonding coefficients is carried out in order to study the interaction between adsorbed complexes and the zeolite framework.

\section{Experimental}

Na Linde $\mathrm{X}$ and $\mathrm{Y}$ zeolites were exchanged following the usual method by using $0.02 \mathrm{M}$ aqueous

Requests for reprints should be sent to Dr. G. MARTINI, Istituto di Chimica Fisica, Via G. Capponi 9, I-50121 Firenze, Italy. solution of the appropriate copper complexes. $\mathrm{Cu}\left(\mathrm{H}_{2} \mathrm{O}\right)_{6}{ }^{2+}$ was introduced from a copper nitrate solution. Copper complexes with $\mathrm{H}_{2} \mathrm{~N}-\mathrm{CH}_{2}-\mathrm{CH}_{2}-\mathrm{NH}_{2}$ (en) and $\left(\mathrm{CH}_{3}\right)_{2} \mathrm{~N}-\mathrm{CH}_{2}-\mathrm{CH}_{2}-\mathrm{N}\left(\mathrm{CH}_{3}\right)_{2}$ (tmen) have been prepared by adding the purified ligand to aqueous solution of copper nitrate up to $\mathrm{Cu}$ /ligand ratio 1:20. Exchange has been carried out from these solutions. The powdered exchanged zeolites were stored in a water-vapour-satured box in order to mantain fully hydrated samples. ESR spectra were registered with a Varian V 4502 spectrometer (X-band) equipped with conventional assembly for temperature variation. Linewidth, g-factor and hfs coupling constant measurements were made by comparison with potassium nitrosodisulphonate $\left(\mathrm{g}=2.0054, \mathrm{a}_{\mathrm{N}}=13.0 \mathrm{G}\right)$.

\section{Results and Discussion}

Both $\mathrm{X}$ and $\mathrm{Y}$ fully hydrated zeolites, after exchange with $\mathrm{Cu}\left(\mathrm{H}_{2} \mathrm{O}\right)_{6}{ }^{2+}$ water solution, show an almost symmetrical ESR signal centered at $\mathrm{g}=2.18$ and linewidth $\sim 150 \mathrm{G}$, as previously observed by NiCUla et al. ${ }^{5}$ and by NACCACHE and BeN TAARIT ${ }^{6}$. The temperature dependence in the region of motional narrowing indicates free rotation of this species in the faujasite cavity ${ }^{3,6}$. From the analysis of the linewidth the correlation time for the reorientation of the complex and for the rapid jump of the Jahn-Teller distortion axis have been previously evaluated ${ }^{3}$.

By freezing out, a complex ESR pattern is obtained (Fig. 1). It indicates the presence of two species characterized by different ESR parameters summarized in the Table I. The first one, which is much more intense, has almost the same parameters as obtained in frozen water solution of $\mathrm{Cu}\left(\mathrm{H}_{2} \mathrm{O}\right)_{6}{ }^{2+}$ and it is clearly due to hydrated $\mathrm{Cu}(\mathrm{II})$ 


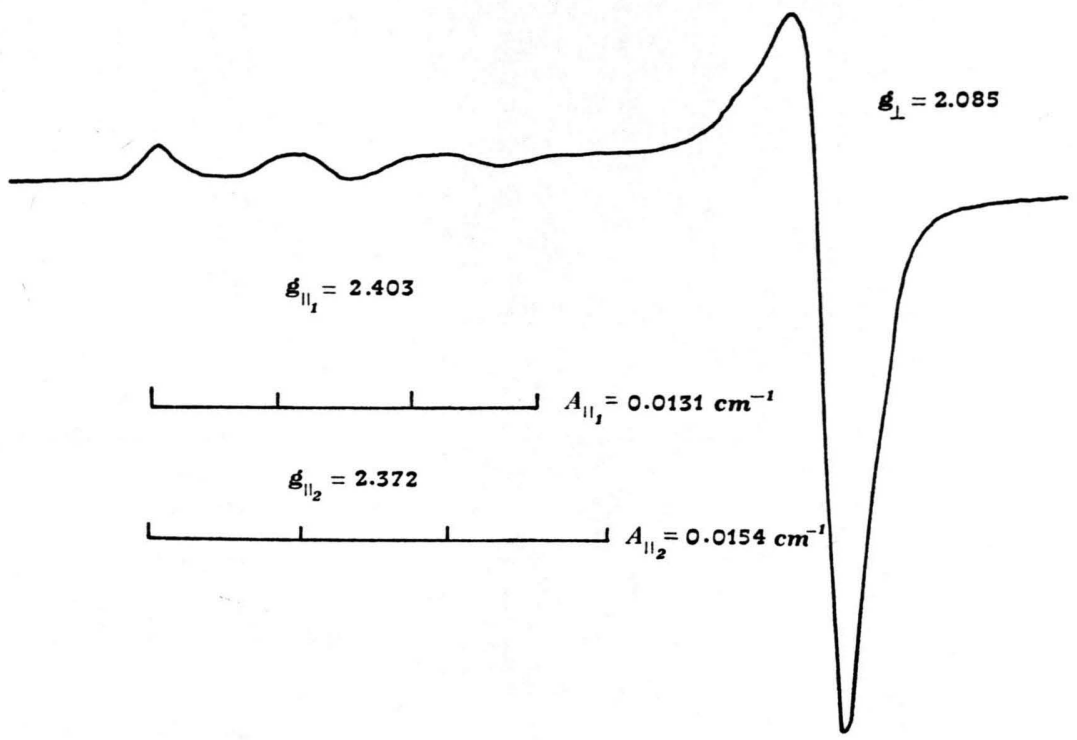

Fig. 1. ESR spectrum of $\mathrm{Cu}\left(\mathrm{H}_{2} \mathrm{O}\right)_{6}{ }^{2+}$ in fully hydrate zeolites at the liquid nitrogen temperature.

Table I. ESR parameters of copper(II) complex.

\begin{tabular}{|c|c|c|c|c|c|c|}
\hline Complex & $\begin{array}{l}\text { Temp. } \\
{\left[{ }^{\circ} \mathrm{C}\right]}\end{array}$ & $g_{\perp}$ & $g_{\|}$ & $\langle\mathrm{g}\rangle^{\mathbf{a}}$ & $\begin{array}{l}A_{\|} \\
{\left[\mathrm{cm}^{-1} \times 10^{4}\right]}\end{array}$ & $\begin{array}{l}\langle\mathrm{A}\rangle^{\mathbf{a}} \\
\text { [Gauss] }\end{array}$ \\
\hline $\mathrm{Cu}\left(\mathrm{H}_{2} \mathrm{O}\right)_{6}{ }^{2+}$ - water & - & 2.095 & 2.401 & 2.195 & -136 & 36.0 \\
\hline $\mathrm{Cu}\left(\mathrm{H}_{2} \mathrm{O}\right)_{6}{ }^{2+}-\mathrm{Y}$ zeolite $\mathrm{I}$ & - & 2.085 & 2.403 & 2.18 & -131 & - \\
\hline $\mathrm{Cu}\left(\mathrm{H}_{2} \mathrm{O}\right)_{6}{ }^{2+}-\mathrm{Y}$ zeolite II & -180 & 2.085 & 2.372 & & -154 & - \\
\hline $\mathrm{Cu}\left(\mathrm{H}_{2} \mathrm{O}\right)_{6}{ }^{2+}-\mathrm{X}$ zeolite $\mathrm{I}$ & - & 2.088 & 2.412 & 2.18 & -128 & - \\
\hline $\mathrm{Cu}\left(\mathrm{H}_{2} \mathrm{O}\right)_{6}{ }^{2+}-\mathrm{X}$ zeolite II & -180 & 2.088 & 2.353 & & -148 & - \\
\hline $\mathrm{Cu}(\mathrm{en})_{2}{ }^{2+}-$ water & - & 2.045 & 2.210 & 2.101 & -200 & 85.6 \\
\hline $\mathrm{Cu}(\mathrm{en})_{2}{ }^{2+}-\mathrm{Y}$ zeolite & 23 & 2.041 & 2.205 & & -193 & - \\
\hline $\mathrm{Cu}(\mathrm{en})_{2}{ }^{2+}-\mathrm{Y}$ zeolite & -180 & 2.039 & 2.210 & & -197 & - \\
\hline $\mathrm{Cu}(\mathrm{en})_{2}^{2+}-\mathrm{X}$ zeolite & 23 & 2.040 & 2.211 & & -192 & - \\
\hline $\mathrm{Cu}(\mathrm{en})_{2}{ }^{2+}-\mathrm{X}$ zeolite & -180 & 2.036 & 2.215 & & -196 & - \\
\hline $\mathrm{Cu}($ tmen $)(\mathrm{OH})_{2}$ - water & - & 2.048 & 2.236 & 2.108 & -187 & 71.4 \\
\hline $\mathrm{Cu}($ tmen $)(\mathrm{OH})_{2}-\mathrm{Y}$ zeolite & 23 & 2.051 & 2.223 & & -186 & - \\
\hline $\mathrm{Cu}($ tmen $)(\mathrm{OH})_{2}-\mathrm{Y}$ zeolite & -180 & 2.045 & 2.236 & & -195 & - \\
\hline $\mathrm{Cu}($ tmen $)(\mathrm{OH})_{2}-\mathrm{X}$ zeolite & 23 & 2.049 & 2.224 & & -187 & - \\
\hline $\mathrm{Cu}($ tmen $)(\mathrm{OH})_{2}-\mathrm{X}$ zeolite & -180 & 2.045 & 2.233 & & -190 & - \\
\hline
\end{tabular}

a Isotropic values of $\mathrm{g}$ and $\mathrm{A}$ are evaluated from room temperature spectra.

trapped in the water filling the supercavity. The second signal can be attributed to copper ions localized on the walls of the cavity (presumably on the $\mathrm{S}_{\text {II }}$ sites $^{6}$ ).

Copper complexes with ethylenediamine (en) and with $\mathbf{N}, \mathbf{N}, \mathrm{N}^{\prime}, \mathrm{N}^{\prime}$-tetramethylethylenediamine (tmen) in water solution at our experimental conditions are predominantly $\mathrm{Cu}(\mathrm{en})_{2}{ }^{2+}$ and $\mathrm{Cu}(\mathrm{tmen})(\mathrm{OH})_{2}{ }^{12,13}$. At room temperature the complexes give rise to isotropic spectra with well resolved four hpf lines (Fig. 2). The ESR parameters at room and liquid nitrogen temperature are reported in the Table $I$.
When adsorbed on synthetic $\mathrm{X}$ and $\mathrm{Y}$ zeolites, they can only enter in the faujasite cavity. The observed spectra are, however, anisotropic even at room temperature with poorly averaged anisotropies of $g$ and $\mathbf{A}$ whose values are similar to those in frozen samples (Fig. 3 and Table I). This fact indicates that in the faujasite cavities of $\mathrm{X}$ and $\mathrm{Y}$ zeolites the large copper complexes, as contrasted with hydrated ions, have very low mobility, with tumbling rate sufficiently slow to prevent averaging of the anisotropies. Similar results have been reported for vanadyl complexes adsorbed on zeolites ${ }^{14}$. Slow 


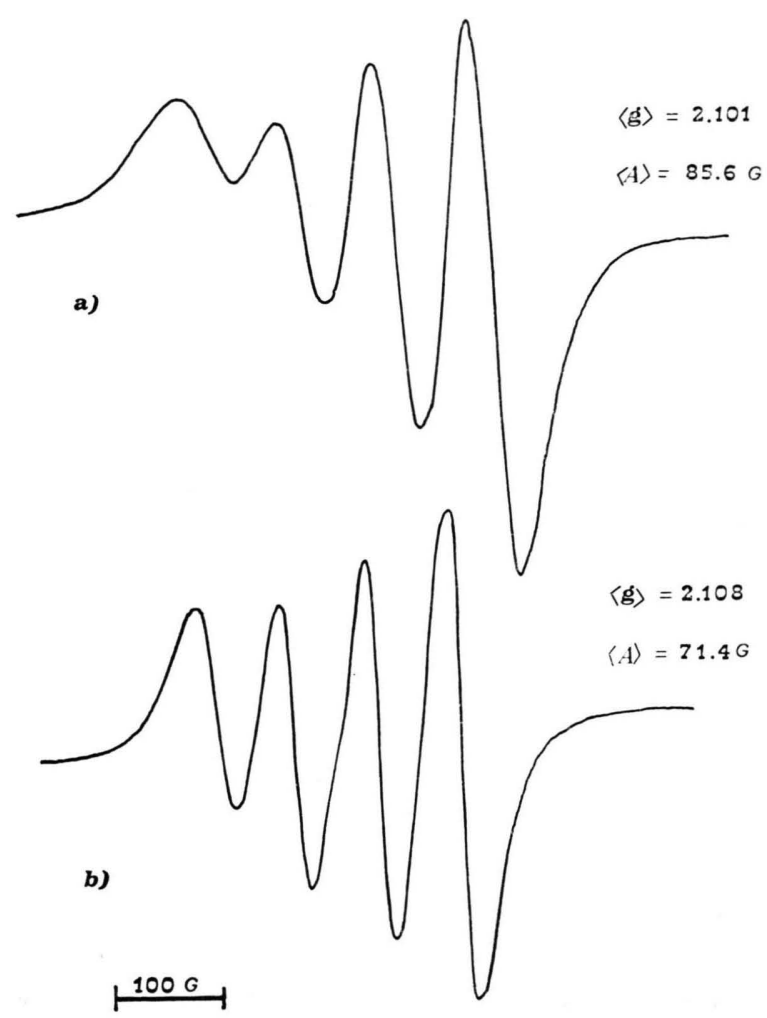

Fig. 2. ESR spectra of $\mathrm{Cu}(\mathrm{en})_{2}{ }^{2+}$ (a) and of $\mathrm{Cu}$ (tmen) $(\mathrm{OH})_{2}(\mathrm{~b})$ in water solution at room tempera. ture.

motion conditions, which are expected for $\tau_{\mathrm{r}}$ in the range $10^{-8}-10^{-10} \sec ^{15-17}$ may be responsible of the observed effects. Indeed, for $\mathrm{Cu}\left(\mathrm{H}_{2} \mathrm{O}\right)_{6}{ }^{2+}$ in fully hydrated zeolites was found $\tau_{\mathrm{r}}=3.6 \times 10^{-10}$ at $25^{\circ} \mathrm{C}^{3}$ and somewhat larger values should be expected for $\mathrm{Cu}(\mathrm{en})_{2}{ }^{2+}$ and $\mathrm{Cu}($ tmen $)(\mathrm{OH})_{2}$. In our opinion the major reason of the anisotropy resides, however, in the steric hindrance which prevents free rotation in the cavity. Strong interactions with the surface cavity seems to be excluded from bonding coefficient calculations (see below).

By evacuation at room temperature no significant variations are observed in the liquid nitrogen spectra for both copper complexes. Irreversible disappearance of the signals occur after vacuum heating above $100^{\circ} \mathrm{C}$. This findings clearly show an irreversible decomposition of the complexes probably to $\mathrm{Cu}$ (II) reduction.

The observed ESR spectra of the copper complexes can be interpreted on the basis of the spin Hamiltonian for $\mathrm{d}^{9}$ ion in axial symmetry:

$$
\begin{aligned}
& +\left(=\mathrm{g}_{\|} \beta \mathrm{H}_{z} \mathrm{~S}_{z}+\mathrm{g}_{\perp} \beta\left[\mathrm{H}_{x} \mathrm{~S}_{x}+\mathrm{H}_{y} \mathrm{~S}_{y}\right]+\right. \\
& \mathrm{A}_{\perp}\left[\mathrm{S}_{x} \mathrm{I}_{x}+\mathrm{S}_{y} \mathrm{I}_{y}\right]+\mathrm{A}_{\|} \mathrm{S}_{z} \mathrm{I}_{z}
\end{aligned}
$$

with $\mathrm{g}_{||}>\mathrm{g}_{\perp}$. Good resolution of the $A_{\mid !}$components was observed, while $A_{\perp}$ components were not resolved. It is surprising that the $\mathrm{Cu}(\operatorname{tmen})(\mathrm{OH})_{2}$ ESR spectrum both in free water and in adsorbed solution is almost axially symmetrical in shape which was not expected since the coordination symmetry of this species must be lower than tetragonal. Since the linewidth of the perpendicular component is quite large, small differences in $\mathrm{g}_{x}$ and $\mathrm{g}_{y}$ might not be observed.

According to the almost axial symmetry and since in all cases $g_{\|}>g_{1}$, we can assume for all the investigated complexes an approximate square planar configuration. We use the treatment of

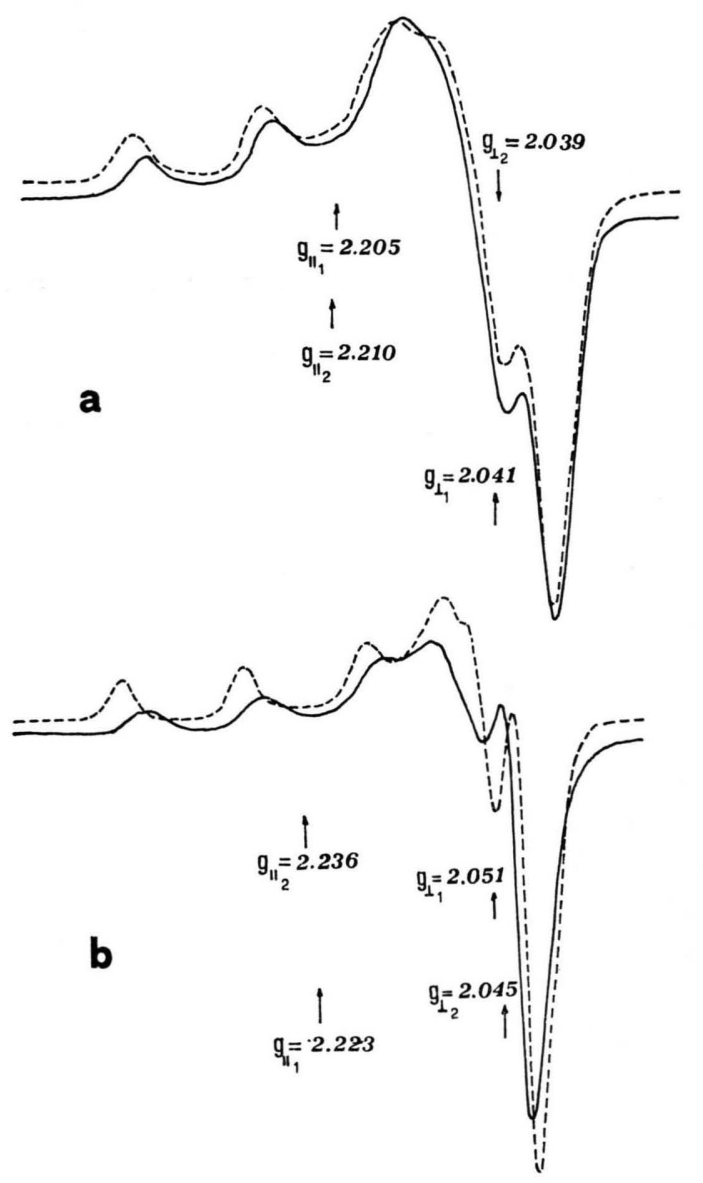

Fig. 3. ESR spectra of copper complexes adsorbed on $\mathrm{Y}$ zeolite:

a) $\mathrm{Cu}(\mathrm{en})_{2}{ }^{2+}$, b) $\mathrm{Cu}($ tmen $)(\mathrm{OH})_{2}$. Full lines: temperature of registration: $23{ }^{\circ} \mathrm{C}$. Dashed lines: temperature of registration: $-180^{\circ} \mathrm{C}$. 
KIVelson and NeIman 18 based on the crystal field analysis of MAKI and MCGARVEY ${ }^{19}$ for copper complexes. The following antibonding wave functions (in the "electron hole" notation) can be formed between the central atom $3 \mathrm{~d}$ and the ligand $2 \mathrm{~s}$ and $2 p$ orbitals :

$$
\begin{aligned}
\psi_{\mathrm{B}_{1 \mathrm{~g}}} & =\beta_{1} \mathrm{~d}_{x^{2}-y^{2}}-\frac{1}{2} \beta_{1}\left[-\sigma_{x}^{(1)}+\sigma_{y}{ }^{(2)}+\sigma_{x}{ }^{(3)}-\sigma_{y}{ }^{(4)}\right] \\
\psi_{\mathrm{B}_{2 \mathrm{~g}}} & =\beta_{2} \mathrm{~d}_{x y}-\frac{1}{2} \sqrt{1-\beta_{2}{ }^{2}}\left[\mathrm{p}_{y}{ }^{(1)}+\mathrm{p}_{x}{ }^{2)}-\mathrm{p}_{y}{ }^{(3)}-\mathrm{p}_{x}{ }^{(4)}\right] \\
\psi_{\mathrm{Eg}} & =\left\{\begin{array}{l}
\varepsilon \mathrm{d}_{x z}-\sqrt{1-\varepsilon^{2}}\left[\mathrm{p}_{z^{(1)}}-\mathrm{p}_{z}{ }^{(3)}\right] / \sqrt{2} \\
\varepsilon \mathrm{d}_{y z}-\sqrt{1-\varepsilon^{2}}\left[\mathrm{p}^{(2)}-\mathrm{p}_{z}{ }^{(4)}\right] / \sqrt{2}
\end{array}\right.
\end{aligned}
$$

where the overlap integrals were included only for the $\psi_{\mathrm{B} 1 \mathrm{~g}}$ wave functions, since their values for $\psi_{\mathrm{B} 2 \mathrm{~g}}$ and $\psi_{\mathrm{Eg}}$ are expected to be small and negligible. The $\sigma_{\mathrm{s}}$ orbitals are sp hybridized:

$$
\sigma^{(\mathrm{i})}=n \mathrm{p}^{(\mathrm{i})} \mp \sqrt{1-n^{2}} \mathrm{~s}^{(\mathrm{i})}
$$

with $0 \leqslant n \leqslant 1$. The $\psi_{\text {A1g }}$ wave function was omitted since it does not affect the magnetic parameters.

The bonding coefficients in eq. (2) give a measure of the covalent character of the in-plane $\sigma$ - and $\pi$-bond ( $\beta_{1}$ and $\beta_{2}$ respectively) and of the out-ofplane $\pi$-bond $(\varepsilon)$. The lower are $\beta_{1}$ and $\beta_{2}$ values, the higher will be the covalent character of the corresponding bonds.

With the above assumptions, resolution of the spin Hamiltonian can be accomplished and equations which relate experimental ESR parameters to the bonding coefficients can be derived. The simplified equation ${ }^{18}$ :

$$
\beta_{1}^{2}=\left|\mathrm{A}_{||}\right| / \mathrm{P}+\Delta \mathrm{g}_{||}+\frac{3}{7} \Delta \mathrm{g}_{\perp}+0.04
$$

can be successfully used for the $\beta_{1}^{2}$ calculation. The $P$ term, defined as :

$$
\mathbf{P}=2 \gamma_{0} \beta_{0} \beta_{\mathrm{N}}\left\langle r_{\mathrm{k}}{ }^{-3}\right\rangle
$$

where $r_{\mathrm{k}}$ is the nucleus-electron distance, can be assumed, according to ABragam et al. ${ }^{20}$ to be $0.036 \mathrm{~cm}^{-1}$. The $\beta_{2}^{2}$ coefficient was calculated from:

$$
\begin{aligned}
& \mathrm{g}_{||}-2.0023=-\frac{8 \lambda \beta_{1} \beta_{2}}{\Delta \mathrm{E}_{x y}} . \\
& {\left[\beta_{1} \beta_{2}-\beta_{1}{ }^{\prime} \beta_{2} \mathrm{~S}-\beta_{1}{ }^{\prime}\left(1-\beta_{2}{ }^{2}\right)^{1 / 2} \mathrm{~T}(n) / 2\right] .}
\end{aligned}
$$

As suggested by several authors ${ }^{18,21}, \varepsilon^{2}$ should be almost unity, thus indicating negligible out-of-plane covalent bonding. $\mathrm{S}$ and $\mathbf{T}(n)$ are respectively the overlap integrals for $\psi_{\mathrm{B} 1 \mathrm{~g}}$ and the integrals over the ligand functions which depend on the metal-ligand distance and on sp hybridazion. The values used for these quantities were taken from the values reported in the literature for oxygen and nitrogen ${ }^{21,22}$ (for $\mathrm{Cu}\left(\mathrm{H}_{2} \mathrm{O}\right)_{6}{ }^{2+}$ and $\mathrm{Cu}(\mathrm{en})_{2}{ }^{2+}$ respectively) and an average of these values for $\mathrm{Cu}(\mathrm{tmen})(\mathrm{OH})_{2}$ (Table II). The transition energies have been taken from several sources 21, 23, 24 and the same values have been used either for water solution or for adsorbed species. Large variations in the transition energies are known to lead to small variations in the bonding coefficients ${ }^{18}$.

Table II summarizes the parameters used and the calculated coefficients. These latter indicate appreciable covalency for $\left|B_{1 g}\right\rangle$ and $\left|B_{2 g}\right\rangle$ while $\left|E_{g}\right\rangle$ orbitals result prevalently ionic in character. In other words, the in-plane $\sigma$ - and $\pi$-bonds are largely covalent while the out-of-plane $\pi$-bond is essentially ionic. No large differences are indeed observed between adsorbed and bulk water complexes. The interaction with charged framework of the supercavity walls seems therefore to be negligible in

\begin{tabular}{|c|c|c|c|c|c|}
\hline Complex & $\beta_{1}^{2}$ & $\beta_{2}^{2}$ & $\mathbf{S}$ & $\mathrm{T}(n)$ & $\Delta \mathrm{E}_{x y}\left[\mathrm{~cm}^{-1}\right]$ \\
\hline $\mathrm{Cu}\left(\mathrm{H}_{2} \mathrm{O}\right)_{6}{ }^{2+}$ - water & 0.86 & 0.79 & $0.076^{\mathrm{a}}$ & $0.220^{\mathrm{a}}$ & $10720^{b}$ \\
\hline $\mathrm{Cu}\left(\mathrm{H}_{2} \mathrm{O}\right)_{6}{ }^{2+}-\mathrm{Y}$ zeolite $\mathrm{I}$ & 0.84 & 0.82 & $0.076^{\mathrm{a}}$ & $0.220^{\mathrm{a}}$ & $10720^{b}$ \\
\hline $\mathrm{Cu}\left(\mathrm{H}_{2} \mathrm{O}\right)_{6}{ }^{2+}-\mathrm{X}$ zeolite $\mathrm{I}$ & 0.84 & 0.81 & $0.076^{\mathrm{a}}$ & $0.220^{\mathrm{a}}$ & $10720^{\mathrm{b}}$ \\
\hline $\mathrm{Cu}(e n) 2^{2+}$ - water & 0.83 & 0.74 & $0.093^{a}$ & $0.333^{a}$ & $18300^{\mathrm{c}}$ \\
\hline $\mathrm{Cu}(\mathrm{en}) 2^{2+}-\mathrm{Y}$ zeolite & 0.81 & 0.76 & $0.093^{a}$ & $0.333^{a}$ & $18300^{\mathrm{c}}$ \\
\hline $\mathrm{Cu}(\mathrm{en})_{2}^{2+}-\mathrm{X}$ zeolite & 0.81 & 0.77 & $0.093^{a}$ & $0.333^{\mathrm{a}}$ & $18300^{\mathrm{c}}$ \\
\hline $\mathrm{Cu}($ tmen $)(\mathrm{OH})_{2}$ - water & 0.81 & 0.81 & 0.084 & 0.277 & $16800^{\mathrm{d}}$ \\
\hline $\mathrm{Cu}($ tmen $)(\mathrm{OH})_{2}-\mathrm{Y}$ zeolite & 0.82 & 0.81 & 0.084 & 0.277 & $16800^{d}$ \\
\hline $\mathrm{Cu}($ tmen $)(\mathrm{OH})_{2}-\mathrm{X}$ zeolite & 0.81 & 0.81 & 0.084 & 0.277 & $16800^{\mathrm{d}}$ \\
\hline
\end{tabular}
modifying the nature of the bond, although the small differences in the coefficients of adsorbed and free charged complexes may find the explanation in this effect.

Thanks are due to the National Council of Research (CNR) for the financial support.

Table II. Molecular orbital parameters of copper(II) complexes.

a See ref. ${ }^{18}$, b see ref. ${ }^{21}$, c see ref. ${ }^{23}$, d see ref. ${ }^{24}$. 
1 L. Burlamacchi, J. Chem. Soc. Faraday Trans. II 71,54 [1975].

2 L. Burlamacchi, G. Martini, and M. F. Ottaviani, J. Chem. Soc. Faraday Trans. II 72, 324 [1976].

3 G. Martini and L. Burlamacchi, Chem. Phys. Lett. 41, 129 [1976].

4 See for instance I. D. Mrkheikin, G. M. ZHIdomirov, and V. B. Kazanskir, Russ. Chem. Rev. 41, 468 [1972].

5 A. Nicula, D. Stamires, and J. Turkevich, J. Chem. Phys. 42, 3684 [1965].

6 C. Naccache and Y. Ben-TaArit, Chem. Phys. Lett. 11, 11 [1971].

7 J. Turkevich, Y. Ono, and J. Soria, J. Catal. 25, 44 [1972].

8 J. T. Richardson, J. Catal. 9, 178 [1967].

9 J. C. Vedrine, E. G. Derouane, and Y. BenTaArit, J. Phys. Chem. 78, 531 [1974].

10 I. R. Leith and H. F. Leach, Proc. R. Soc. (London) Ser. A 330, 247 [1972].

11 J. Marti, J. Soria, and F. H. Cano, J. Phys. Chem. 80,1776 [1976].

12 G. H. McIntyre, B. P. Block, and W. C. FerneLIUs, J. Am. Chem. Soc. 81, 529 [1959].
13 E. Arenare, P. Paoletti, A. Dei, and A. Vacca, J. Chem. Soc. Dalton Trans. 1972, 736.

14 G. Martini, M. F. Ottaviani, and G. L. Seravalli, J. Phys. Chem. 79, 1716 [1975].

15 J. H. Freed, G. V. Bruno, and C. F. Polnaszek, J. Phys. Chem. 75, 3385 [1971].

16 C. F. Polnaszek, G. V. Bruno, and J. H. Freed, J. Chem. Phys. 58, 3185 [1973].

17 S. A. Goldman, G. V. Bruno, C. F. Polnaszek, and J. H. Freed, J. Chem. Phys. 56, 716 [1972].

18 D. Kivelson and R. Neiman, J. Chem. Phys. 35, 149 [1961].

19 A. H. Maki and B. R. McGarvey, J. Chem. Phys. 29, 31 [1958].

20 A. Abragam, J. Horowitz, and M. H. L. Pryce, Proc. R. Soc. (London) Ser. A 230, 169 [1955].

21 W. B. Lewis, M. Alei (Jr.), and L. O. Morgan, J. Chem. Phys. 44, 2409 [1966]; 45, 4003 [1966].

22 M. R. Gersman and J. D. Swalen, J. Chem. Phys. 36, 3221 [1962].

23 G. Gordon and R. K. Birdwhistell, J. Am. Chem. Soc. 81, 3567 [1959].

24 Y. FukudA and K. Sone, Bull. Chem. Soc. Jpn. 45, 465 [1972]. 